\title{
The Establishing Operation Revisited
}

\author{
Bruce E. Hesse \\ California State University, Stanislaus
}

Over 10 years have passed since the publication of Michael's argument for a clear distinction between the motivational and discriminative functions of stimuli in our technical language (Michael, 1982). The student of behavior analysis will now find reference to establishing operations (EOs) in at least four current classroom texts (Catania, 1992; Cooper, Heron, \& Heward, 1987; Malott, Whaley, \& Malott, 1993; Martin \& Pear, 1992). Each lists the term "establishing operation" in their subject index, and at least one (Catania, 1992) incorporates the EO language in several chapters (10 separate page references were given in the subject index along with a definition in the glossary). It appears that the EO language is making its way into our behavioral vocabulary.

Michael's current presentation of the EO adds to his previous work by including extensive descriptions (with examples) of unconditioned establishing operations (UEOs) of positive and negative reinforcement as well as positive and negative punishment. He also describes and categorizes learned (or conditioned) motivative variables (the conditioned establishing operation). His systematic and thorough presentation of the complex issues is noteworthy (although a complete understanding of some sections requires a familiarity with his previously published terminology refinements and distinctions).

As Michael points out, motivation as a general topic does not appear in the behavioral literature, and for good reason. The traditional view of motivation as an inner agent adds nothing. However, the facts giving rise to this view still need to be explained, and the typical behavioral treatments seem incomplete. Mi-

Correspondence concerning this article should be addressed to Bruce E. Hesse, Psychology Department, CSU-Stanislaus, Turlock, CA 95380. chael's emphasis on environmental "operations" that produce certain results (i.e., they establish the effectiveness of particular stimuli as consequences and alter the probability of behavior related to those stimuli) is needed. Any analysis of contingencies involving environmental circumstances, behavior, and consequences would be incomplete without reference to why the consequences were effective in those circumstances.

\section{Terms and the Multiple Functions of Stimuli}

After reading Michael's paper, it was clear that the title "Establishing Operations" represents only part of his message. He also attempts to improve our technical language with respect to discriminative stimuli $\left(\mathrm{S}^{\mathrm{D}}\right)$ and the multiple functions of stimuli. His terminological lessons on the $S^{D}$ were very complete (and frequent), but this was necessary because the specific conditions for the use of the term discriminative stimulus is central to distinguishing between the evocative effects of the EO and those of the $S^{D}$. Many people use the term without carefully considering its appropriateness. His inclusion of unique terms (e.g., unconditioned elicitor [UE], unconditioned conditioner [UC], conditioned elicitor [CE], and conditioned conditioner [CC]) illustrates that EO effects are part of a long list of stimulus functions that should be considered when analyzing behavior. However, these terms need more clarification before their meaning can be fully appreciated. Although these various stimulus functions may be difficult (or impossible) to separate in an experimental analysis, their consideration is required for a thorough interpretation. Consider his description of what happens with the onset of a painful stimulus. This one event has many simultaneous effects. It functions as a respondent elicitor of 
some unlearned response (the UE effect) and at the same time alters the function of neutral stimuli (conditions them) to elicit similar responses in the future if a contingency exists (the UC effect). In the operant area, the painful stimulus establishes its own offset as reinforcement and evokes behavior that accomplished this offset in the past (the unconditioned establishing operation effect related to negative reinforcement). The stimulus onset probably weakened the behavior just preceding it (as an unconditioned punisher) and it might have conditioned contiguous neutral stimuli to function as conditioned punishers in the future. Perhaps it evoked behavior that was more likely to be reinforced by something other than pain reduction (the discriminative stimulus effect). Consideration of all these functions demonstrates a thorough analysis of the theoretical possibilities. One question that must be asked is whether all the theoretical possibilities produced by the logical extension of a concept have significance in reality. For example, is anything gained by considering every possible stimulus function, and is it meaningful to attempt to assess these functions experimentally? For a unified theory of behavior, I think the answer is yes.

\section{The Unconditioned Establishing Operation (UEO)}

In illustrating the various ways in which the EO perspective can be employed when considering unconditioned positive and negative reinforcement, Michael raises several interesting points. Of particular interest is his suggestion that elicited aggression might better be characterized as a UEO effect (the pain makes signs of damage to others an effective reinforcer and also evokes the behavior that produced such damage). Relating this to other "emotional" EOs clarifies the "predisposition" aspect of the operant account of emotion and is useful in interpreting dramatic shifts in human behavior when strong emotions are evident.

The argument for an EO of unconditioned punishment seems less compel- ling when considering stimulus presentation, withdrawal, or removal. For stimulus presentation, Michael points out that the punishing stimulus functions as it own EO (an apparent redundancy in terms). For stimulus removal or withdrawal, we need specify only the reinforcement $\mathrm{EO}$ because withdrawal or removal of that reinforcer produces the behavior decrease we call punishment, and it is that EO that "establishes" withdrawal or removal as an effective consequence.

\section{The Conditioned Establishing Operation (CEO)}

Conditioned reinforcement and punishment play important roles in the control of human behavior, and a complete understanding of each is critical to behavior analysis. Michael's discussion of variables that alter the reinforcing effectiveness of other events due to conditioning is particularly valuable. His conditioned establishing operation (CEO) is theoretically appealing. Of the three discussed (surrogate $\mathrm{CEO}$, reflexive $\mathrm{CEO}$, and transitive $\mathrm{CEO}$ ), the transitive CEO seems difficult to validate experimentally. Previously published studies with nonhumans (McPherson \& Osborne, 1986,1988 ) have clearly shown the evocative effects of the putative CEO stimulus. The difficult part is measuring changes in conditioned reinforcing effectiveness directly related to the presence or absence of the CEO. Typical experimental procedures used to study conditioned reinforcement effects (i.e., shaping a new response using the putative conditioned reinforcer or using a concurrent chains procedure to assess "choice") are difficult to use due to the transitory nature of the reinforcing stimulus. Thus, demonstrating that the conditioned reinforcing or punishing effectiveness of particular consequences can be "turned on or off' by the presentation or removal of a critical stimulus may require novel methodology and experimental subjects able to develop quickly histories involving conditional relations. It is clearly an important concept that deserves extensive study. 


\section{Concluding Comments}

In summary, the EO approach to the analysis of the facts of motivation is most promising. Michael's analysis represents a detailed and thorough account of important issues relevant to the field of behavior analysis. I hope that others will consider these issues carefully and apply them to their experimental research as well as to the interpretation of practical problems. Behavior analysis is not the simplistic, strictly linear model of human behavior its critics claim. The points raised by Michael concerning multiple functions of stimuli and discrimination between motivation and discriminative variables illustrate this nicely. His use of background references related to behavioral accounts of motivation, the extensive use of examples illustrating his main points, and his systematic and detailed approach to this very complex theoretical area were particularly helpful. More research and discussion of the EO are anticipated.

\section{REFERENCES}

Catania, A. C. (1992). Learning (3rd ed.). Englewood Cliffs, NJ: Prentice-Hall.

Cooper, J. O., Heron, T. E., \& Heward, W. L. (1987). Applied behavior analysis. Columbus, $\mathrm{OH}$ : Merrill Publishing Company.

Malott, R. W., Whaley, D. L., \& Malott, M. E. (1992). Elementary principles of behavior (2nd ed.). Englewood Cliffs, NJ: Prentice-Hall.

Martin, G., \& Pear, J. (1992). Behavior modifcation, what it is and how to do it (4th ed.). Englewood Cliffs, NJ: Prentice-Hall.

McPherson, A., \& Osborne, J. G. (1986). The emergence of establishing stimulus control. Psychological Record, 36, 375-386.

McPherson, A., \& Osborne, J. G. (1988). Control of behavior by an establishing stimulus. Journal of the Experimental Analysis of Behavior, 49, 213227.

Michael, J. (1982). Distinguishing between discriminative and motivational functions of stimuli. Journal of the Experimental Analysis of Behavior, 37, 149-155. 